\title{
Kreativitas Dan Budaya (Studi Kasus Creative Director Etnis Tionghoa Dalam Industri Peri- klanan)
}

\author{
Tashya Elvira Agatha, Gregorius Genep Sukendro \\ tashyaeagatha@gmail.com,geneps@fikom.untar.ac.id \\ Fakultas Ilmu Komunikasi Universitas Tarumanagara
}

\begin{abstract}
Chinese ethnicity is closely related to attitudes or behaviors related to themselves and other groups. The creativity and culture of the Chinese ethnic Creative Director in the advertising industry is considered as a person of Chinese ethnicity who is creative especially in the advertising industry. When linked, the background of Chinese teaching also has a role in forming a creative personality. This research tells about the relationship between Chinese culture (teaching, work ethic) that is owned by the Creative Director and his creative life, especially in carrying out his role. The underlying theories include, Human Philosophy, Ethnic Theory, Chinese Ethnicity in Indonesia, Creative Individual Theory, Creative Personality Formation, Advertising Theory, Creative Department, Creative Director. The research is qualitative in style with a descriptive approach, and a case study method. The data used are primary data and secondary data. Primary data collection is done by in-depth interviews with them, creative Chinese ethnic creative directors. Meanwhile, secondary data is obtained through literature and documents. In this study, it was shown that the culture of ethnic Chinese contributed to the formation and creation of a creative creative director.
\end{abstract}

Keywords: Chinese Ethnicity, Creative Director, Creative

\begin{abstract}
Abstrak
Etnis Tionghoa erat hubungannya dengan sikap ataupun perilaku yang berkaitan dengan diri mereka dan kelompok lain. Kreativitas dan budaya dari Creative Director beretnis Tionghoa dalam industri periklanan dianggap sebagai seseorang beretnis Tionghoa yang kreatif terutama dalam berkreasi di industri periklanan. Bila dikaitkan, latar belakang pengajaran Tionghoa pun memiliki peran dalam pembentukan pribadi kreatif. Penelitian ini melihat keterkaitan antara budaya (pengajaran, etos kerja) Tionghoa yang dimiliki oleh Creative Director dengan kehidupan kreatifnya terutama dalam menjalani peranannya. Teori yang mendasari antara lain, Teori Filsafat Manusia, Teori Etnis, Etnis Tionghoa di Indonesia, Teori Individu Kreatif, Teori Pembentukan Pribadi Kreatif, Teori Periklanan, Creative Departement, Creative Director. Penelitian bergaya kualitatif dengan pendekatan deskriptif, dan metode studi kasus. Data yang digunakan adalah data primer dan data sekunder. Pengumpulan data primer dilakukan dengan wawancara mendalam kepada mereka, Creative Director beretnis Tionghoa yang kreatif. Sedangkan, data sekunder diperoleh melalui literatur dan dokumen-dokumen. Dalam penelitian ini menunjukan bahwa budaya dari Etnis Tionghoa berkontribusi dalam pembentukan dan proses terciptanya sustu pribadi creative Director yang kreatif.
\end{abstract}


Kata Kunci : Etnis Tionghoa, Creative Director, Kreatif

\section{Pendahuluan}

Kreativitas seringkali dikaitkan dengan seni, karena seni merupakan media yang memberi banyak ruang untuk mengasah kreativitas. Padahal, sebenarnya kreativitas bisa diwujudkan dalam berbagai bentuk. Misalnya lewat ilmu pengetahuan, teknologi, karya kreatif lain yang bersifat fungsional, bahkan dalam beriklan. Maraknya ide-ide kreatif yang ada dan meningkatnya perkembangan industri kreatif membuat interaksi antar individu melahirkan dan mewariskan suatu kebudayaan.

Kebudayaan tentunya dimiliki Indonesia yang merupakan negara kepulauan yang penuh dengan kekayaan serta keragaman budaya, ras, suku bangsa, kepercayaan, agama, bahasa daerah, dan masih banyak lainnya. Salah satu dari keberagaman budaya itu adalah etnis Tionghoa.

Etnis Tionghoa sebagian besar sebagai pedagang yang menjadi relasi para penguasa. Pada Era Orde Lama kegiatan etnis Tionghoa di Indonesia tidak terlihat berkembang secara signifikan. Mereka mayoritas berprofesi sebagai pedagang, dalam keseharian kita sering mendengar sebutan "cukong". Istilah "cukong" adalah pengusaha Tionghoa yang kaya dan biasanya memiliki hubungan dekat pihak penguasa (Suryadinata, 2005: 135).

Pada Era Orde Baru kegiatan etnis Tionghoa di Indonesia tidak banyak mengalami perubahan. Sebagian besar etnis Tionghoa masih dominan bergerak di sektor perniagaan dibandingkan dengan kegiatan politis. Sangat sedikit sekali etnis Tionghoa yang terjun di ranah politik ataupun pemerintahan.

Etnis Tionghoa merupakan kumpulan orang yang memiliki berbagai macam tradisi yang telah mengakar kuat. Seringkali mereka sendiri tidak memahami betul apa yang mendasari kebiasaan dan tingkah lakunya. Namun, seiring berjalannya waktu mereka mampu menyesuaikan diri dalam abad modern seperti saat ini. Tradisi tetap banyak dinyatakan dalam bentuk sikap, dalam nuansa perilaku, pola pikir serta dalam kegiatan tertentu, dan bukan dalam diskusi terbuka yang membahas benar atau tidaknya suatu masalah.

Penelitian ini menjadi menarik dan penting untuk mengkaji dan mengungkap kondisi orang sebagai etnis Tionghoa yang berprofesi menjadi Creative Director dalam mengkaji peranannya di dunia kreatif, indutri periklanan. Jadi diharapkan melalui penelitian ini dapat menemukan dan menggali Kreativitas Dan Budaya (Studi Kasus Creative Director Etnis Tionghoa dalam Industri Periklanan).

Berdasarkan latar belakang yang telah diuraikan diatas, maka permasalahan yang akan dikaji dalam penelitian ini, yaitu:

1. Bagaimana tradisi budaya Tionghoa mengakar kuat terhadap kreativitas seorang creative director yang berketurunan Tionghoa?

Berdasarkan latar belakang masalah dan rumusan masalah di atas, maka diperoleh tujuan penelitian sebagai berikut:

1. Untuk mengetahui bagaimana kaitan budaya yang telah mengakar terhadap kreativitas yang dicapai.

2. Untuk mengetahui mengapa ada etnis Tionghoa dapat berprofesi sebagai Creative Director yang kreatif. 
Tashya Elvira Agatha, Gregorius Genep Sukendro: Kreativitas Dan Budaya (Studi Kasus Creative Director Etnis Tionghoa Dalam Industri Periklanan)

\section{Metode Penelitian}

Tipe Penelitian yang digunakan adalah deskriptif yaitu memaparkan subyek penelitian. Tipe penelitian ini didasarkan pada pertanyaan dasar yaitu "bagaimana" (Gulo, 2010: 19). Jenis penelitian yaitu menggunakan metode kualitatif. Pada penelitian kualitatif tidak merumitkan penghitungan angka pada statistika sosial tetapi lebih menekankan pada data-data dari hasil observasi dan wawancara peneliti dengan informan yang dituangkan dalam tulisan baku.

Studi kasus merupakan pengujian secara rinci terhadap satu latar atau satu orang subjek atau satu tempat penyimpanan dokumen atau satu peristiwa tertentu. Membatasi pendekatan studi kasus sebagai suatu pendekatan dengan memusatkan perhatian pada suatu kasus secara intensif dan rinci.

Subjek dan Objek Penelitian Moleong (2010: 132) mendeskripsikan subjek penelitian sebagai informan, yang artinya orang pada latar penelitian yang dimanfaatkan untuk memberikan informasi tentang situasi dan kondisi latar penelitian.

Subyek yang dimaksud adalah, mereka creative director etnis Tionghoa (ada keturunan) sebagai individu kreatif. Objek penelitian merupakan hal yang menjadi titik perhatian dari suatu penelitian. Titik perhatian tersebut berupa substansi atau materi yang diteliti atau dipecahkan permasalahannya menggunakan teori-teori yang bersangkutan. Obyek yang dimaksud adalah, pola pikir atau perilaku hidup kreatif sebagai creative director beretnis Tionghoa.

Kriteria narasumber dalam penelitian ini, Creative Director yang memiliki keturunan Tionghoa, Kreatif dalam arti telah memperoleh penghargaan dalam hasil karya kreatif dalam industri periklanan, berjenis kelamin laki-laki usia kurang lebih 30-50 tahun, tidak harus berlatar belakang pendidikan advertising, berdomisili Indonesia.

Teknik Pengumpulan Data Pengumpulan data dilakukan untuk memperoleh informasi yang dibutuhkan dalam rangka mencapai tujuan penelitian (Gulo, 2010: 110). Data yang akan dikumpulkan dalam penelitian diantaranya: literatur, hasil observasi, wawancara mendalam, dan dokumen. Pengumpulan data dilakukan untuk memperoleh informasi yang dibutuhkan dalam rangka mencapai tujuan penelitian.

Analisis data digunakan dalam penelitian deskriptif untuk menggambarkan analisis data di lapangan. Analisis data pada penelitian ini menggunakan teknik triangulasi. Triangulasi dengan pemeriksaan keabsahan data. Triangulasi dilakukan dalam pengecekan data untuk memperoleh keyakinan terhadap kebenaran data pada penelitian kualitatif.

\section{Hasil Temuan dan Diskusi}

\section{Informan Paulus Soni C Gumilang}

Paulus Soni C Gumilang, creative director beretnis Tionghoa yang kreatif di dalam industri periklanan. Dengan latar belakang pendidikan dari:

- Sarjana Teknik (ST) Architecture Department, Atma Jaya University, Yogyakarta $(1995-2001)$

- Magister Ilmu Komunikasi (M.Si) Marketing Communication Department, Post Graduate Programme London School of Public Relations - Jakarta (2006 2008)

Saat ini Soni bekerja di Fortune Indonesia. Karena Soni begitu aktif dalam industri kreatif ini, tentunya banyak penghargaan yang telah diperolehnya. Lowe Worldwide 
Creative League Finalist London, Unilever $75^{\text {th }}$ anniversary campaign Finalist Communications Campaign of the Year in Asia category Stevie Awards New York, dan masih banyak lagi.

Informan Galvin Sanusi

Galvin Sanusi, creative director beretnis Tionghoa yang kreatif di dalam industri periklanan. Dengan latar belakang pendidikan dari Billy Blue, Graphic \& Advertising School Sydney (1993-1996), banyak pengalaman kerja sebagai creative director yang telah dialaminya, yaitu :

- Art Director di Ammirati Puris Lintas - Link (1996-1999)

- Sr.Art Director di Leo Burnett (2000-2003)

- Creative Group Head di Lowe Indonesia (2003-2005)

- Associate Creative Director di Lowe Indonesia (2005-2006)

- Creative Director di Saatchi\&Saatchi (2006-2008)

- Creative Director di Grey (2008-2011)

- Creative Director di Dentsu Indonesia (2011-2013)

- Creative Director di Advantage (2013-2014)

- Executive Creative Director di TCP TBWA (2014-2017)

- Creative Director di WOW Communication (2017- sekarang).

Galvin telah menciptakan karya untuk merek regional dan merek lokal seperti Unilever, Levi's, Pantene, Olay, Mead Johnson, Wyeth, Nestle, Toyota, Sharp, Telkomsel, Hoka-hoka Bento, Nippon Paint, Djarum Cigarette, Sampoerna Hijau Cigarette, Mitu Baby, Darya Varia, Soho, Datsun, Ultra Jaya, Ponsel Lenovo, Traveloka, dan masih banyak lagi.

Informan Stevie Sulaiman

Stevie Sulaiman, creative director beretnis Tionghoa yang kreatif di dalam industri periklanan. Dengan latar belakang pendidikan dari DKV Universitas Petra, Surabaya (1999 - 2003), banyak pengalaman kerja sebagai creative director. Saat ini Stevie bekerja sebagai Head of Creative, StratX Kompas Gramedia. tevie Sulaiman atau lebih akrab dipanggil Stevie juga tentunya telah berkarya dalam industri kreatif ini untuk merek regional dan merek lokal, dan yang dikreativitaskan pada tahun 2018 adalah digital campaign NESCAFÉ, digital campaign Bear Brand Ramadhan 2018 \& Hari Kemerdekaan 2018, dan masih banyak lagi.

Dalam proses untuk menjadi seorang yang kreatif masing-masing individu memiliki proses yang berbeda-beda. Hal ini dipengaruhi oleh latar belakang yang beragam. Untuk menjadi Individu yang kreatif, Paulus Soni C Gumilang dipengaruhi oleh lingkungan saat berproses.

Soni sejak kecil diasuh oleh banyak orang dengan latar belakang dan karakter yang berbeda-beda. Ini yang membuatnya punya banyak pengaruh dalam proses pembentukan diri menjadi seorang kreatif. Setelah kuliah, Soni makin "intens" bersinggungan dengan dunia kreatif. Kuliah di jurusan arsitektur karena suka menggambar, ikut mendirikan beberapa band sampai bikin lagu, dan bertemu banyak orang-orang kreatif karena kuliah di Jogja. "Di sini juga saya mulai berkenalan dengan advertising sejak aktif di sebuah radio lokal, bertemu banyak orang dengan keunikan masing-masing adalah sumber inspirasi saya untuk menjadi seorang kreatif". "Banyaknya referensi adalah keharusan, tidak bisa kita menolak untuk mencoba apapun, karena itu bagian dari pengalaman yang memperkaya imajinasi kita".

Bagi Soni, pengaruh kebudayaan dalam pembentukan gaya hidup kreatif tidak begitu berpengaruh. Menurutnya, tradisi mengenai gaya hidup yang bertekat kuat dalam mencapai sesuai (pantang menyerah) tidak cukup kuat. "Yang paling penting 
Tashya Elvira Agatha, Gregorius Genep Sukendro: Kreativitas Dan Budaya (Studi Kasus Creative Director Etnis Tionghoa Dalam Industri Periklanan)

adalah tidak takut untuk bekerja di mana saja. Bisa bekerja di manapun dengan siapapun. Kompetitif, selalu ingin bisa lebih baik dari sesama kreatif yang lain."

Soni tidak terlalu merasakan pengalaman diskriminasi. Kalaupun ada itu hanya terbatas di lingkungan kampung tempat saya tinggal tapi itu menjadikan alasan saya untuk menjadi yang terbaik sehingga menunjukkan pada mereka bahwa golongan yang mereka diskriminasi akhirnya jauh lebih berhasil daripada hidup mereka".

Tidak jauh berbeda dengan Soni. Galvin Sanusi juga dipengaruhi oleh lingkungan saat berproses untuk menjadi individu kreatif. Keluarga dan orangtua Galvin, cenderung membebaskan dirinya. Pengalaman lebih Galvin dapatkan saat memasuki Agency multinasional di Lowe dan pengaruh lingkungan serta mentoring. Pada saat itu Lowe masih bernama Citra Lintas "disitulah saya belajar mengenai disiplin ilmunya dan kebetulan saya morning person, dan pada saat itu banyak bule jadinya bos-bos kita tuh bule bule yang memang disiplin banget dalam bekerja".

Latar belakang pendidikan Galvin, advertising dan design. Orangtua tidak membatasi Galvin dalam memilih jurusan yang diminatinya. Galvin memiliki rasa ambisius dalam berkarya dengan harapan akan dapatnya penghargaan. Rasa ambisiusnya itu ditopang dengan adanya daya juang dan pengajaran tidak cepat puas serta pantang menyerah. Galvin cenderung melihat insight yang ada dan menciptakan konsep yang baru "killers idea".

Galvin pernah mengikuti kelas workshop bersama Leo Burnett, banyak perwakilan-wakilan dari negara lain yang juga ikut serta. "Kalo kita ngomong etnis ya memang benar si kebanyakan tim Singaporian yang chinese-chinese gitu lebih ambisi banget daya juangnya tinggi."

Sedangkan, Stevie Sulaiman terlahir dari keluarga yang tidak berlatar seni. Ayahnya insinyur teknik sipil yang juga hobi berdagang otomotif, dan ibunya dulu sekretaris untuk perusahaan perindustrian Jerman di Surabaya. Awal ketertarikannya pada dunia kreatif lewat otomotif, dan sempat berpikir untuk belajar desain otomotif, tapi pada saat itu Stevie kurang punya akses dan modal untuk studi mancanegara, jadi Stevie mencari bidang desain di dalam negeri yang cukup mendekati minat utamanya. Tahun 1998 saat Stevie SMA, Universitas Petra membuka DKV dan diterima ketika mengikuti tes masuknya.

"Secara mendasar, proses mendapatkan ide kreatif tidak mudah tapi tidak sampai rumit yang luar biasa. Selalu berawal dari observasi, baik observasi problem/opportunity dan observasi audiens". Hasil observasi ini menjadi data atau insight, dan makin mendalam insight-nya, makin membuat Stevie tertuju pada ide-ide yang fresh. Semacam ketika sedang mempersiapkan kejutan untuk orang yang berarti, semakin mengenalnya, semakin spesial kejutan dan ucapan yang diberikan. Tentunya karena advertising ini bisnis, kita juga tidak boleh melupakan faktor kemasan.

Dalam individu Stevie, pengetahuan seputar kebudayaan dan budaya serta pengajaran sebagai keturunan etnis Tionghoa melekat dan berpengaruh bagi Stevie. Determinasi adalah salah satu modal utama untuk menjadi kreatif, karena proses berkreasi ini panjang dan tidak mudah. "Jadi, ya, pantang menyerah adalah modal yang mutlak harus dimiliki". "Kebiasaan hidup efisien ( $\neq$ pelit ya :p) juga aset yang berharga, karena membantu kita menciptakan inovasi-inovasi baru yang dapat mengefisiensikan operasional sebuah usaha, atau bahkan mengefisiensikan sebuah experience". 
Setelah mendeskripsikan hasil dari wawancara mendalam, maka hasil wawancara tersebut akan dipadukan berdasarkan teori dan hasil dokumentasi. Analisis yang diberikan mengacu pada tanggapan diberikan terhadap pertanyaan-pertanyaan yang dilontarkan oleh saya.

Dalam diri seorang creative director terdapat "Eros" yaitu daya kreatif dalam dirinya. Sehingga karena adanya Eros tersebut mendorong diri meraka untuk berpikir kreatif serta menjadi individu yang kreatif. Eros dimiliki oleh setiap individu, namun dengan kadar yang berbeda-beda. Hal tersebut tentunya dipengaruhi oleh aspekaspek lain, terutama lingkungan yang berpengaruh.

Keberhasilan etnis Tionghoa dalam berbagai bidang khususnya industri kreatif sering kali menimbulkan berbagai pertanyaan. Banyak yang bertanya-tanya bagaimana etnis Tionghoa bisa begitu kreatif dalam bidang. Etnis Tionghoa memulai segalanya dari bawah, dari yang tadinya tidak mempunyai apa-apa akhirnya menjadi orang kreatif. Semuanya itu tidak diperoleh begitu saja, tetapi dengan perjuangan yang keras.

Tradisi mengenai gaya hidup yang bertekat kuat dalam mencapai sesuai (pantang menyerah) tidak cukup kuat bagi sebagian dari mereka. "Yang paling penting adalah tidak takut untuk bekerja di mana saja. Bisa bekerja di manapun dengan siapapun. Kompetitif, selalu ingin bisa lebih baik dari sesama kreatif yang lain."

Perjuangan keras mereka (creative director beretnis Tionghoa) tidak secara mutlak dipengaruhi oleh budaya yang diwariskan secara turun temurun. Namun, mereka mengatakan bahwa "fighting spirit" atau daya juang begitu besar untuk mencapai atau memperoleh sesuatu. Daya juang yang kuat ini memang merupakan suatu budaya turunan yang mengakar kuat. Determinasi juga adalah salah satu modal utama untuk menjadi kreatif, karena proses berkreasi ini panjang dan tidak mudah. Kebiasaan hidup efisien juga aset yang berharga, karena membantu mereka menciptakan inovasi-inovasi baru yang dapat mengefisiensikan operasional sebuah usaha, atau bahkan mengefisiensikan sebuah experience.

\section{Simpulan}

Dalam proses untuk menjadi seorang yang kreatif, masing-masing individu memiliki proses yang berbeda-beda. Hal ini dipengaruhi oleh latar belakang yang beragam. Berdasarkan penelitian ini, untuk menjadi individu beretnis Tionghoa yang kreatif, mereka cenderung dipengaruhi oleh faktor lingkungan, diskriminasi tidak begitu mereka rasakan. Jika ya, itu menjadikan alasan untuk menjadi yang terbaik sehingga menunjukan pada mereka bahwa golongan yang mereka diskriminasi akhirnya jauh lebih berhasil daripada hidup mereka.

Etos kerja etnis Tionghoa atau perjuangan keras mereka (creative director beretnis Tionghoa) tidak secara mutlak dipengaruhi oleh budaya yang diwariskan secara turun temurun. Namun, fighting spirit dari budaya turunan etnis Tionghoa terhadap perilaku dan pola pikir daya juang tetap mendarah daging. Determinasi juga adalah salah satu modal utama untuk menjadi kreatif, karena proses berkreasi ini panjang dan tidak mudah. Kebiasaan hidup efisien juga aset yang berharga, karena membantu mereka menciptakan inovasi-inovasi baru yang dapat mengefisiensikan operasional sebuah usaha, atau bahkan mengefisiensikan sebuah experience.

Creative director beretnis Tionghoa lebih banyak memperoleh inspirasi untuk kreatif dalam "bermain" di luar ruang, bertualang, menjelajah, dan "blusukan" ke berbagai tempat, "Nongkrong" dan ngobrol bersama teman. Dengan melihat tren 
yang sedang booming dan berinteraksi dengan lingkungan juga merupakan hal yang mereka lakukan. Sebagai pimpinan pada bagian kreatif, mereka terbiasa untuk memberikan transparansi dan kejelasan serta "sense of belonging". Mereka berusaha semaksimal mungkin untuk mendorong "tim" agar bekerja secara maksimal dalam berkreativitas terhadap karya.

\section{Ucapan Terima Kasih}

Pada kesempatan ini, saya menyampaikan ucapan terima kasih atas bantuan, dukungan, petunjuk, saran, nasehat, bimbingan, dan kesempatan yang telah diberikan selama penulisan skripsi ini. Sehingga proses penelitian dan penyusunan skripsi ini dapat berjalan dengan baik dan lancar.

Adapun ucapan terima kasih ini penulis tujukan kepada, Tuhan Yang Maha Esa, Ibu Dr. Riris Loisa, M.Si selaku Dekan Fakultas Ilmu Komunikasi Universitas Tarumanagara, Bapak Yugih Setyanto, S.Sos., M.Si selaku Wakil Dekan Fakultas Ilmu Komunikasi Universitas Tarumanagara, Bapak Gregorius Genep Sukendro, S.Sos., M.Si. selaku dosen pembimbing, Orang tua dan keluarga, Narasumber yang telibat, semua pihak yang membantu dalam penelitian dan skripsi ini, baik secara langsung mau pun tidak langsung yang tidak dapat disebutkan satu per satu membantu penulis menemukan referensi dan ide-ide terkait dengan penulisan skripsi.

\section{Daftar Pustaka}

Fitrawan,Nur. (2011_. Skripsi Etika agama etnis tionghoa dalam peningkatan ekonomi di kel. Melayu baru kec. Gajo kota Makassar

Herawati, Anita. Jurnal Persepsi Creative Director Tentang Penggunaan Budaya dalam Kreatif Iklan pada Merek Global (Studi Kasus Persepsi Tentang Penggunaan Budaya Universal dalam Iklan TVC Oreo Ice Cream Flavor di Indonesia dan Arab Saudi dari Sudut Pandang Creative Director Biro Iklan di Yogyakarta)

Moleong, L. J. (2010). Metodologi Penelitian Kualitatif, Bandung: Remaja Rosda Karya

Seng, Ann Wan. (2008). Rahasia Bisnis Orang Cina. Cet. VIII. Jakarta: Hikmah (PT Mizan Publika)

Sukendro, G. Genep (2017). Kreativitas Indonesia: Analisis Iklan Pariwisata Indonesia "Pesona Indonesia" Jakarta: Jurnal Fakultas Ilmu Sosial dan Ilmu Politik Universitas Muhammadiyah Sidoarjo, Sidoarjo - Indonesia

Suryadinata, Leo. (2005). Pemikiran Politik Etnis Tionghoa Indonesia. LP3ES. Jakarta.

Tumanggor, Rusmin. Dkk . (2010). Ilmu Sosial dan Budaya Dasar. Kencana. Jakarta.

W. Gulo, (2010). Metode Penelitian 